\title{
A SPECTRAL METHOD FOR FOURTH-ORDER BOUNDARY VALUE PROBLEMS
}

\author{
NADRA BOUARROUDJ, LEKHMISSI BELAIB, and BEKKAI MESSIRDI
}

\begin{abstract}
Boundary-value problems for fourth-order partial differential equations are studied in this paper; more precisely, vibrational phenomena of plates in an incompressible non-viscous fluid along the edge are mathematically analyzed. The spectral method via the variational formulation is used to prove existence, uniqueness and regularity theorems for the strong solution. We discuss also a discrete variational formulation for the considered problem.
\end{abstract}

MSC 2010. 34A12, 35J40, 35J50.

Key words. Spectral method, fourth-order problem, boundary condition.

\section{REFERENCES}

[1] R. Bellman, Dynamic Programming, Princeton University Press, Princeton, 1957.

[2] X.H. Yu and B.Yu Guo, Spectral element method for mixed inhomogeneous boundary value problems of fourth order, J. Sci. Comput., 61 (2014), 673-701.

[3] J.L. Lions, Contrôle optimal de systèmes gouvernés par des équations aux dérivées partielles, Paris, Dunod, 1968.

[4] J.L. Lions, Quelques méthodes de résolution des problèmes aux limites non linéaires, Paris, Dunod, 1969.

[5] H. Saker and N. Bouselsal, On the bilaplacian problem with nonlinear boundary conditions, Indian J. Pure Appl. Math., 47 (2016), 425-435.

[6] E. Şen, On spectral properties of a fourth-order boundary value problem, Ain Shams Engineering Journal, 4 (2013), 531-537.

[7] P.-A. Raviart and J.-M. Thomas, Introduction à l'analyse numérique des équations aux dérivées partilles, Paris, Dunod, 1998.

Received January 22, 2018

Accepted March 19, 2018

The authors thank the referee for his helpful comments and suggestions.

DOI: $10.24193 /$ mathcluj.2018.2.02 
ENP Oran Maurice Audin

Department of Mathematics and Informatics

Oran, Algeria

E-mail: nadra.bouarroudj@gmail.com

University of Oran 1 Ahmed Ben Bella

Department of Mathematics

Oran, Algeria

E-mail: belaib_lekhmissi@yahoo.fr

Laboratory of Fundamental and Applicable

Mathematics of Oran (LMFAO)

Oran, Algeria

E-mail: bmessirdi@yahoo.fr 